\title{
Equity market volatility using garch models- evidence from Pakistan stock exchange (kse-100 index)
}

\author{
Muhammad Asif *, Abdul Aziz \\ Lecturer Federal Urdu University of Arts, Science and Technology Karachi \\ *Corresponding author E-mail:muhammad.aseeph@gmail.com
}

\begin{abstract}
Purpose - The purpose of this paper is to investigate the cluster volatility of return distribution in the Pakistan Stock exchange (PSX) formerly named Karachi stock exchange (KSE-100 Index). GARCH model for characterizing financial market volatility is discussed. Design/methodology/approach - This study used daily time series of the market index PSX (KSE-100) data over the period from January 1st, 2008 to December 31st, 2015, 1983 observations have been collected from KSE website.ARCH family models have been used, such as GARCH, EGARCH, PGARCH and TARCH models, to estimate cluster volatility. SIC, AIC, and Log likelihood have been used to select the appropriate model.

Findings - GARCH 1,1 model is found the most appropriate model among ARCH family models. The outcome of this study indicates that the Pakistan Stock Exchange is weak-form efficient and explains cluster volatility and leptokurtic distribution.

Research limitations/implications - Re-composing of Karachi stock exchange 100 index.

Practical implications - Stock market returns' behavior changes according to daily basis available information, which is helpful for the investors to maximize their portfolio's return and managing the risk.

Originality/value - Karachi stock market (KSE-100 Index) volatility from 2011 to 2015.
\end{abstract}

Keywords:Stock Market; Volatility; GARCH; EGARCH; TARCH; PSX; Pakistan.

\section{Introduction}

There are three fundamental purposes to forecast volatility; they are risk management, assets allocation, and taking bets. A vast portion of risk management is to measure the potential future misfortunes of a portfolio of assets, and keeping in mind the targeted goal to gauge these potential misfortunes. These gauges must be made of future volatilities and correlations.

This research investigates the significance of GARCH models in explaining stock return dynamics and volatility on the Pakistan Stock Exchange. The share price valuation in the stock market is one of the most important and focal point in the field of finance research. The capital market analysts are interested to understand the which factors are influence on the movement of share prices The upward trend in volatility is a cause of declining in equity price examined by (Malkiel, 1979). The Autoregressive Conditional Heteroscedasticity $(\mathrm{ARCH})$ process was introduced by (Engle, 1982). ARCH imposes an autoregressive formation on conditional variance and allocates volatility shocks to persist over time. This persistence captures the tendency of returns of like magnitude to cluster in time and can explain the well-documented non-normality and non-stability of empirical assets return distributions (Fama, 1965). Pakistan Stock Exchange (PSX) established on 1st January 2016 after the merger of all three stocks markets namely (Karachi stock exchange, Lahore stock exchange, and Islamabad stock exchange). On this study, we will focus exclusively on KSE-100 Index, which is the benchmark of the Pakistan capital market. The Pakistan stock exchange comprises of six different indices for the convenient of the investors. Pakistan stock exchange comprise of six different indices for the convenient of the investors.

i) KSE-All Companies Index.(Karachi Stock Exchange All Companies Index).

ii) KSE-100 Index(Karachi Stock Exchange 100 Companies Index).

iii) KSE-30 Index(Karachi Stock Exchange 30 Companies Index).

iv) KMI-30 Index (Karachi Meezan Islamic 30 Companies Index).

v) BK TI (Banking Tradable Index)

vi) OGTI (Oil \& Gas Tradable Index)

The investors are very much concerned with risk and return.The risk management strategy is based on volatility. The financial market return's volatility fluctuates between positive and negative zones and mostly fund managers and investors awfully serious concerns about negative returns.But it's true "High-risk intensity follows by abnormal gain". Mean reversion basic cause of volatility and another hand is Mean fleeing if $\alpha+\beta>1$. The oscillations of a risk premium in the capital market and volatility persistence are examined by using GARCH family models (Chou, 1988). Mandelbrot (1963) and Fama (1965) both provided evidence that major changes in an assets price are often followed by other big changes, small changes are often followed by small changes.

A Random walk is defined by the facts that price movement or fluctuation are independent of each other and no any historical effect on current price and unpredictable (Brealey, Myers and Allen, 2005). Under the random walk hypothesis, a market is weak-form efficient if the most recent price contains all available information. In the strictest version of the efficient market hypoth- 
esis, et is not only random and stationary, and also shows no autocorrelation, since the disturbance or error term cannot acquire any systematic predict errors. The theory of random walks says that the future path of the price level of a security is no more predictable than the path of a series of cumulated random numbers. In statistical terms, the theory says that successive price changes are independent, identically distributed random variables. Most simply this implies that the series of price changes has no memory, that is, the past cannot be used to predict the future in any meaningful way (Fama 1965). The numerous models were developed to evaluate the assets pricing volatility for the determining financial market risk need the inference of a volatility parameter. The information is the key input factor of the volatility and volatility is helpful for the portfolio diversifications and hedging fund. The fluctuation of the financial assets price returns either up or down is called volatility. High volatility raises the financial risk which can be the unfavorable impact on investor assets. Share prices follow the information and quickly absorb the new information. The new information about the economic indicators can be attributed in the increasing volatility. This type of volatility is not dangerous because there is no social cost affiliated with it. But against this phenomenon, if the increase in volatility fails to explain the economic indicator, it is harmful because it misprices the stocks (Karmaka, 2006). The perception of "Market efficiency" is vital to understand the working of stock markets of the world. The random walk argues that the price of the future is independent of the price today, prices may be determined by the daily economic situation; latest price may not be useful for predicting future prices. As one market follows a random walk means that it has no patterns on the market and any new information that is available immediately reflected in stock prices and investors abnormal profits cannot win by identifying trends or patterns. A leptokurtic distribution has more observations around the mean and in the tails than does a normal distribution. Leptokurtosis appears also in stock prices (FAMA).

\subsection{Volatility}

Volatility is the standard deviation of log returns. High volatility means returns are highly risky or there is high fluctuation in returns and low volatility means that low risk and low fluctuation. "The estimate of future volatility will depend on upon information in today's information set such as today's returns. Volatility is said to be persistent if today's return has a large effect on the forecast variance many periods in the future" (Engle and Patton,2001) Any information can because of escalating volatility trim down the demand for a stock because of risk aversion. The results turn down in stock value is pursued by the increased volatility as forecast by the available information. The inference of such clustering volatility is that volatility shocks today will pressure the anticipation of volatility many periods in the future.

\subsection{Object of study}

The objective of this study is to make sure the PSX follow the random walk or not and check the efficiency in its weak-form in Pakistan Stock Exchange. The purpose of the study is to identify that a technical investor that uses historical trends and events to forecast future prices can earn the benefit from PSX or not.

\subsection{Literature review}

Several studies investigated the performance of GARCH models in explaining the volatility of emerging stock markets. Ronald Mangani (2005) and Tuyen, (2011) examined expected return and volatility of stock market using GARCH models, results show that volatility is prevalent on the market, it is established that the effects of shocks on volatility are symmetric and that volatility is not a commonly priced factor. Ahmed (2011) study Khartoum Stock Exchange (KSE) period from Jan 2006 to Nov 2010 and result show that high level of persistence in the stock market which indicates low-risk aversion
Chou (1988) focused on Malkiel and Pindycy's hypothesis on chaos in U.S. capital marketin 1974. He used GARCH models and claimed that $4.5 \%$ risk aversion in U.S. market. Sabrina Khanniche (2015) studied hedge fund risk their volatility and using symmetric (GARCH) and asymmetric (EGARCH and TGARCH) models used to evaluate a 1-day-ahead value at risk (VAR), and find GARCH family models are very much appropriate.

Baillie and Myers (1991) applied Bi-variate GARCH model cash and future in commodities prices. The optimal hedge ratio (OHR) is then calculated as a ratio of the conditional covariance between cash and futures to the conditional variance of futures. Lux and Marchesi (2000) studied the both chartist and fundamentalist approach. Price transform is brought about by market speculators were re-acting to inequity between demand and supply. The clustered volatility was clarified as the outcome of the market being the focus to rare short-term volatility.

Liu and Shrestha (2008) observed the relation between the macrofactors and share prices in the China stock market and found that strongrelationship. Beltratti and Morana (2006) examined the association among macroeconomic and capital market volatility, using S\&P500 data for the period 1970-2001. They were found confirmation of both long memory and structural change in the volatility process. Short term rates and M1 growth seem to be the most closely associated variables.

\subsection{Data}

The data consist of 1983 daily trading observations of the PSX (KSE-100 index) from the period 01 January 2008 to 31 December 2015 obtained from www.psx.com.pk. We have use EViews7 is to estimate and forecast GARCH models.

\section{Methodology}

The volatility is based on standard deviation and forecasting volatility of the assets returns based on conditional heteroscedasticity model. The standard GARCH $(\mathrm{p}, \mathrm{q})$ model expresses the variance at time t . $\sigma^{2} t_{+1}=\omega+\alpha \mu^{2} t+\beta \sigma^{2}$ t. The volatility estimate is based on GARCH model.GARCH model has three different factors one for the conditional mean equation, one for the conditional variance, and one for the conditional error, the information set available at time $\mathrm{t}-1$.

GARCH model is $\sigma^{2} t_{+1}=\omega+\alpha \mu^{2} t+\beta \sigma^{2} t$

\section{Where}

$\sigma^{2} t_{+1}=$ Tomorrow's return volatility (variance)

$\omega=$ Omega

$\alpha \mu^{2} \mathrm{t}=$ Alpha coefficient oftoday return Mean square

$\beta \sigma^{2} \mathrm{t}=$ Beta coefficient oftodayreturn variance

"When $\alpha+\beta<1$, the variance process displays mean reversion to the unconditional expectation of $\sigma^{2}$ t. $\omega /(1-\alpha-\beta)$. That is, forecasts of volatility in the distant future will be equal to the unconditional expectation of $\sigma^{2}$ t. $\omega /(1-\alpha-\beta) "$. (Neely, et al .2002). The Risk Metrics model for volatility forecasting imposes the restrictions that $\alpha+\beta=1$ and that $\omega=0$. In addition, the parameter $\beta$ is not estimated, but imposed to be equal to 0.94 (J.P. Morgan/Reuters, 1996).

$\operatorname{GARCH}(1,1)$ almost sure positivity of requires, $\sigma^{2} \mathrm{t}$

With the conditions that (Nelson and Cao),

$\omega \geq 0$

$\alpha \geq 0$ 


\section{$\beta \geq 0$}

The Omega is a product of two factors lambda and long term average volatility. Omega shows the rate of volatility.

Omega $=\lambda \cdot V_{L}$

$\lambda . V_{L}=$ Gamma rate of long term average volatility

If $\lambda$ equal to zero GARCH come to VaR model is $\sigma^{2} t_{+1}=\alpha \mu^{2} t+\beta \sigma^{2} t$

$\lambda$ is show persistence factor 'higher value of lambda give more weight to older data lower value of lambda higher weight to recent data. High persistence associated with slow decays, low persistence associated with fast decays. If Alpha + Beta $=1$; we will use an Integrated GARCH (IGARCH) process. Efficient markets hypothesis (EMH) defines that in an efficient market share price fully reflect the available information. There are three shapes or stages of the efficient market hypothesis that differ in what infor- mation is considered. Weak-form version of EMH asserts that prices of financial assets reflect all information contained in the past prices. Semi-strong version hypothesizes that share prices reflect all the publicly available information. Lastly, strong-form hypothesizes that share prices reflect, in addition to information on past prices and publicly available information, inside information (Fama, 1970). Karachi stock market is high volatility due to insider trading by collusive stock brokers.

Numerous statistical tests for random walks have been used in the literature. The most popular variance ratio is tested by (Lo and MacKinlay,1988). The serial correlation test of returns has also been used extensively (See Kendell (1953), Moore (1962), Godfrey (1964), and Fama (1965). These random walk's tests are based on the independent identical distribution (iid) assumptions. The GARCH $(1,1)$ model is also used to capture the main characteristics of financial time series such as volatility clustering, stationarity and fat-tails. The GARCH model will additionally be used to discover the presence of nonlinear autoregressive conditional heteroscedasticity $(\mathrm{ARCH})$ property which says the opposite of the random walk concept. Results \& Analysis.

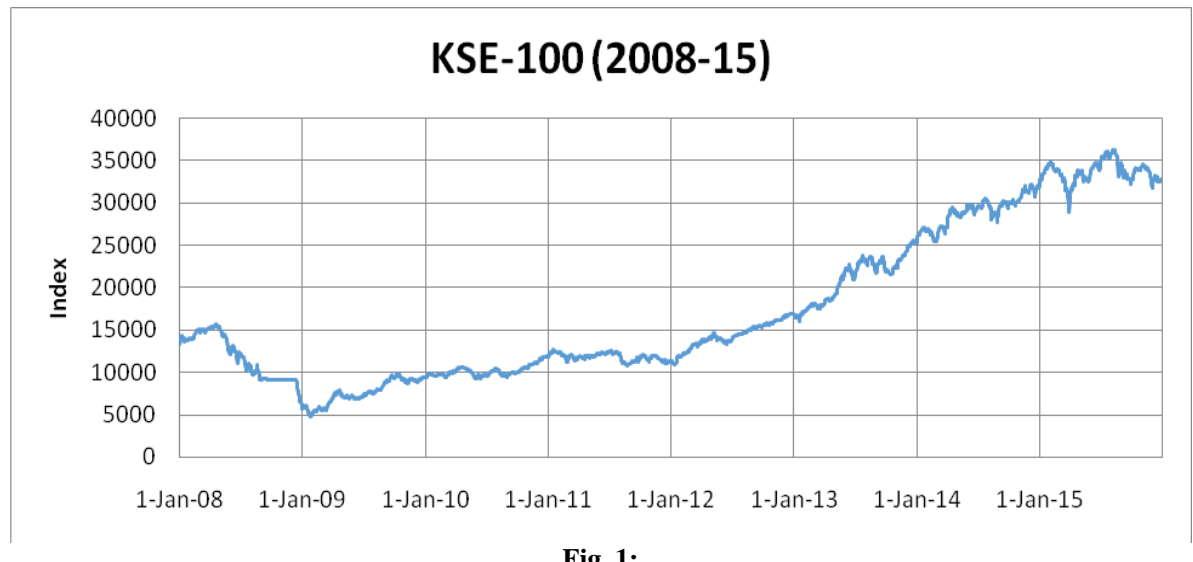

Fig. 1:

In 2008 due to global financial crises KSE-100 show decline about 1/3, after that 2009 to 2012 was recovery section and 2013 to 2014 showed sharply upward trend and break past index levels with high volatility as against past years, In 2015 broke all resistance levels and touch to 35,456 highest index level but due to political \& terrorism PSX fail to maintain their level and that period show very high volatility.

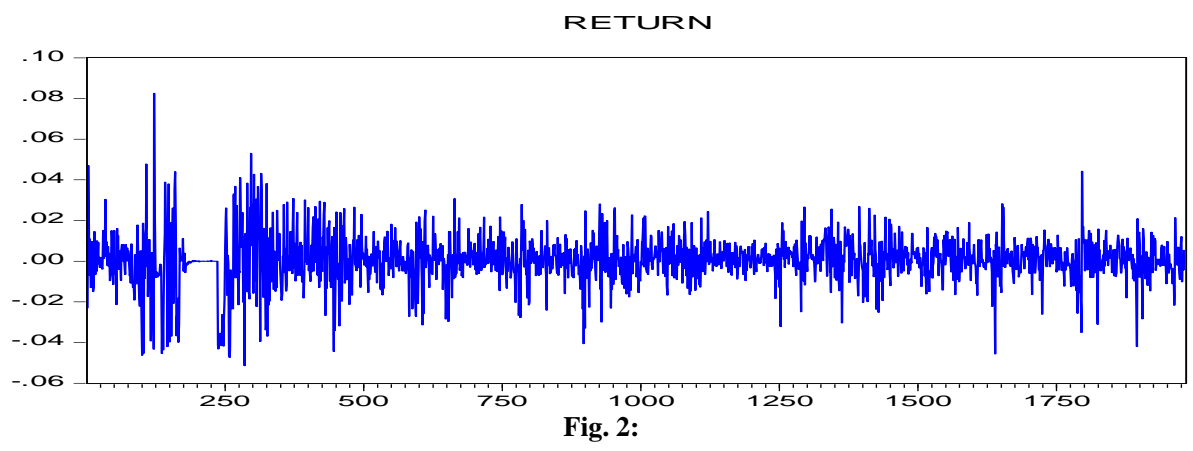

Table 1:

\begin{tabular}{ll}
\hline \multicolumn{2}{c}{ Table 1: } \\
\hline Descriptive Statistic & $2008-15$ \\
\hline Mean & 0.00044 \\
Median & 0.00044 \\
Maximum & 0.08255 \\
Minimum & -0.05135 \\
Std. Dev. & 0.01184 \\
Skewness & -0.24006 \\
Kurtosis & 7.10325 \\
Jarque-Bera & 1409.46500 \\
Probability & 0.00000 \\
Observations & 1982 \\
\hline
\end{tabular}




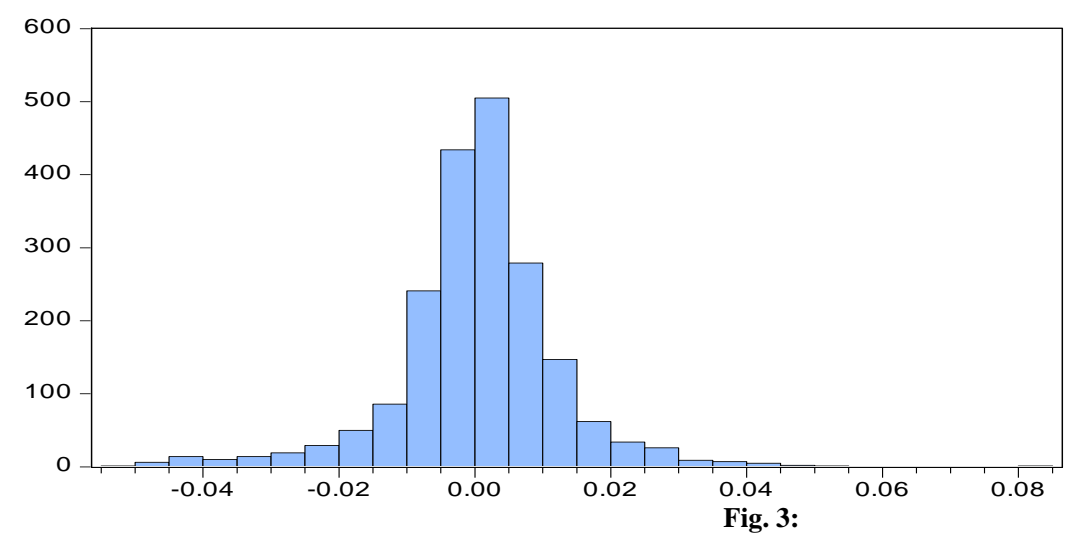

Series: RETURN

Sample 11983

Observations 1982

Mean

0.000442

Median

0.000442

Maximum 0.082547

Minimum $\quad-0.051349$

Std. Dev. $\quad 0.011840$

Skewness $\quad-0.240060$

Kurtosis $\quad 7.103251$

Jarque-Bera 1409.465

Probability 0.000000

In 2008-15 the result of descriptive statistics shows that the average daily return $\ln (\mathrm{Rt}=\operatorname{lnRt} 1 / \operatorname{lnRt})$ the range between 0.00044 to 0.05135 .The average daily return of the KSE-100 close to zero and high Std. deviation which means that there are high volatility and risk nature of the market. The skewness coefficient points out that the returns distribution is significantly and negatively skewed; the returns also show that the negative skewness in its distribution, indicating the greater chance of extremely negative outcomes. PSX daily returns are leptokurtic or fat-tailed. The kurtosis or degree of excess, in the PSX returns, is greater than the normal value of 3 .

Stationary Test.

Table 2: KSE-100 Index ADF and PP Unit Root Test Results at Levels

\begin{tabular}{|c|c|c|c|c|}
\hline \multicolumn{5}{|c|}{ Null Hypothesis: KSE100 Index has a unit root } \\
\hline $\begin{array}{l}\text { Type of } \\
\text { test }\end{array}$ & t-statistic & $\begin{array}{l}\text { Critical } \\
1 \% \text { level }\end{array}$ & $\begin{array}{l}\text { Critical 5\% } \\
\text { level }\end{array}$ & Inference \\
\hline ADF test & 0.70912 & -3.433452 & -2.862796 & $\mathrm{tH} 0$ \\
\hline PP test & 0.708894 & -3.433450 & -2.862796 & Not reject $\mathrm{HO}$ \\
\hline
\end{tabular}

Table 3:KSE-100 Index Returns ADF and PP Unit Root Test Results at Levels

\begin{tabular}{lllll}
\hline $\begin{array}{l}\text { Null Hypothesis: KSE100 Index returns has a unit root } \\
\text { Type of } \\
\text { test }\end{array}$ & t-statistic & $\begin{array}{l}\text { Critical 1\% } \\
\text { level }\end{array}$ & $\begin{array}{l}\text { Critical 5\% } \\
\text { level }\end{array}$ & Inference \\
\hline $\begin{array}{l}\text { ADF test } \\
\text { PP test }\end{array}$ & -36.79 & -3.433 & -2.863 & reject H0 \\
\hline
\end{tabular}

Testing non-stationarity is essential for the random walk hypotheses, The above results of Augmented Dickey and Fuller and Phil Personshow that the all null hypothesis reject and accept the alternative hypothesis as the $\mathrm{p}$-value is less than the $1 \%$ significant at the 1st level of the unit root test. Conclude that the PSX is market efficient at the weak-form level.

\begin{tabular}{lllll}
\multicolumn{5}{c}{ Table 4: } \\
\hline & GARCH 11 & TARCH & EGARCH & PGARCH \\
\hline Akaike info & -6.37671 & -6.40766 & -6.41554 & -6.42129 \\
Schwarz & -6.36543 & -6.39356 & -6.40143 & -6.40436 \\
\hline
\end{tabular}

Akaika information criterion (AIC) and SIC are the best tools to choose the appropriate model. The SIC and Akaike Information Criterion (AIC) have been widely used in the ARCH-GARCH literature. The results in table 4 show that GARCH 1,1 is the best model.

GARCH 1, 1 Table 5:

\begin{tabular}{|c|c|c|c|c|}
\hline \multicolumn{5}{|l|}{ Variance Equation } \\
\hline Variable & Coefficient & Std. Error & z-Statistic & Prob. \\
\hline$\Omega$ & $5.94 \mathrm{E}-06$ & $4.16 \mathrm{E}-07$ & 14.28147 & 0 \\
\hline$\alpha$ & 0.165359 & 0.013715 & 12.0571 & 0 \\
\hline$\beta$ & 0.791296 & 0.01267 & 62.4545 & 0 \\
\hline Durbin-Watson stat & 1.614025 & & & \\
\hline Log likelihood & 6323.321 & & & \\
\hline$\alpha+\beta$ & 0.957 & & & \\
\hline VL & 0.00000621 & & & \\
\hline
\end{tabular}


Correlogram Q statistic Test

Table 6:

\begin{tabular}{|c|c|c|c|c|}
\hline & $\mathrm{AC}$ & PAC & Q-Stat & Prob \\
\hline 1 & 0.146 & 0.146 & 42.263 & 0.000 \\
\hline 2 & 0.041 & 0.020 & 45.659 & 0.000 \\
\hline 3 & 0.023 & 0.014 & 46.701 & 0.000 \\
\hline 4 & 0.052 & 0.047 & 52.040 & 0.000 \\
\hline 5 & 0.031 & 0.017 & 54.003 & 0.000 \\
\hline 6 & 0.018 & 0.009 & 54.671 & 0.000 \\
\hline 7 & 0.013 & 0.007 & 55.001 & 0.000 \\
\hline 8 & -0.012 & -0.019 & 55.304 & 0.000 \\
\hline 9 & 0.000 & 0.002 & 55.304 & 0.000 \\
\hline 10 & 0.056 & 0.056 & 61.495 & 0.000 \\
\hline 11 & 0.020 & 0.003 & 62.270 & 0.000 \\
\hline 12 & -0.004 & -0.010 & 62.309 & 0.000 \\
\hline 13 & 0.008 & 0.009 & 62.424 & 0.000 \\
\hline 14 & 0.033 & 0.027 & 64.568 & 0.000 \\
\hline 15 & 0.017 & 0.005 & 65.142 & 0.000 \\
\hline 16 & 0.027 & 0.022 & 66.613 & 0.000 \\
\hline 17 & 0.023 & 0.014 & 67.704 & 0.000 \\
\hline 18 & 0.041 & 0.034 & 71.110 & 0.000 \\
\hline 19 & 0.004 & -0.009 & 71.144 & 0.000 \\
\hline 20 & 0.025 & 0.018 & 72.417 & 0.000 \\
\hline 21 & 0.009 & -0.002 & 72.571 & 0.000 \\
\hline 22 & 0.001 & -0.004 & 72.571 & 0.000 \\
\hline 23 & -0.046 & -0.049 & 76.814 & 0.000 \\
\hline 24 & -0.010 & -0.002 & 76.999 & 0.000 \\
\hline 25 & 0.009 & 0.011 & 77.164 & 0.000 \\
\hline 26 & 0.005 & 0.002 & 77.209 & 0.000 \\
\hline 27 & -0.017 & -0.017 & 77.765 & 0.000 \\
\hline 28 & -0.011 & -0.009 & 78.015 & 0.000 \\
\hline 29 & 0.040 & 0.045 & 81.274 & 0.000 \\
\hline 30 & 0.035 & 0.022 & 83.737 & 0.000 \\
\hline 31 & -0.009 & -0.023 & 83.898 & 0.000 \\
\hline 32 & -0.029 & -0.030 & 85.632 & 0.000 \\
\hline 33 & -0.022 & -0.013 & 86.607 & 0.000 \\
\hline 34 & -0.000 & 0.002 & 86.607 & 0.000 \\
\hline 35 & 0.012 & 0.009 & 86.900 & 0.000 \\
\hline 36 & -0.003 & -0.007 & 86.913 & 0.000 \\
\hline
\end{tabular}

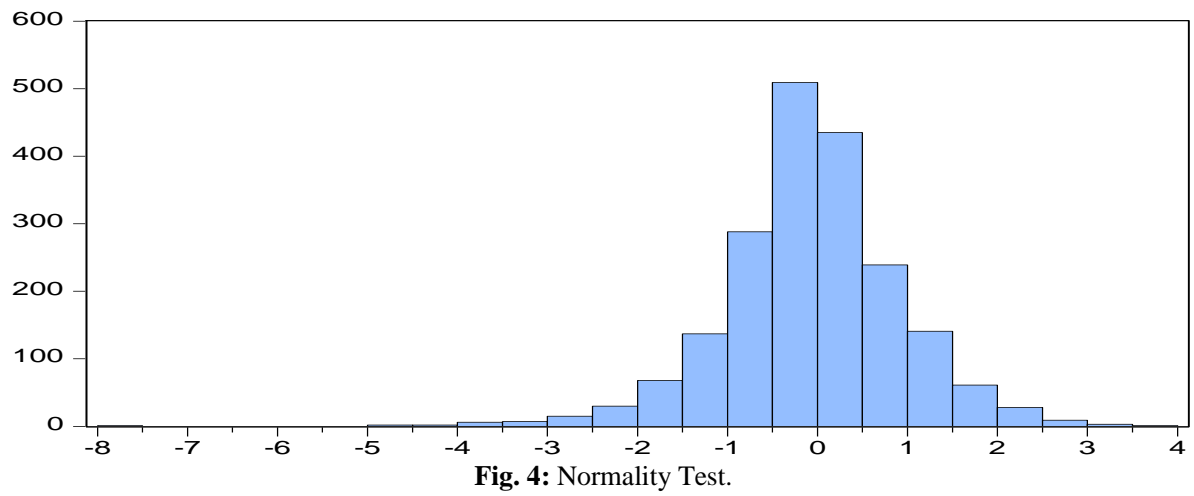

GARCH 1,1 model results primarily reject random walk hypothesis. High persistence equates to slow decay and slow "regression toward the mean;" low persistence equates to rapid decay and quick "reversion to the mean." GARCH coefficient $(\alpha+\beta)$ is very close to 1 , that demonstratingthe volatility shocks are quite a persistence. High persistence of volatility clusters on the market. This is an indication of inefficiency. Furthermore, the coefficient of lagged conditional variance is significantlypositive and less than one indicate the impact of old news on volatility is significant meaning that large changes tend to be followed by large changes and the reverse is true (Mandelbrot, 1963).

Table 8: Variance Ratio Tests

\begin{tabular}{|c|c|c|}
\hline \multicolumn{3}{|c|}{ Null Hypothesis: RETURN is a random walk } \\
\hline \multicolumn{3}{|c|}{ Assume no heteroskedasticity } \\
\hline Period & z-Statistic & P-value \\
\hline 2 & -19.54942 & 0 \\
\hline 4 & -17.02463 & 0 \\
\hline 8 & -12.63861 & 0 \\
\hline 16 & -9.388312 & 0 \\
\hline
\end{tabular}

Variance ratio analysis was used to test the random walk hypothesis for the markets under study. variance ratio test result shows that Pakistan stock exchange daily return data do not follow random walks.

\section{Conclusion}

Market efficiency one of the most important area for financial researchers. This paper investigated the issue of weak-form efficiency on the Pakistan Stock Exchange (KSE-100) for the period 2008 to 2015 . The main analytical models: GARCH $(1,1)$ model has been employed to test for significant random walks and volatility of the market.

The outcome of this study indicates that the Pakistan Stock Exchange is weak-form of market efficient. The Results from the GARCH models and other nonparametric tests generally reject the presence of random walks in the PSX daily market returns. The 
lack of random walks a mark of market inefficiency and assumes that assets pricing and risk are the misrepresentation in the market. On the whole, the outcomes from this study give confirmation to show volatility clustering and leptokurtic distributionfor the Pakistan stock exchange on the basis of daily returns data. These conclusions are tuned with international evidence of financial data exhibiting the phenomenon of volatility clustering and fat-tailed distribution. The long run volatility annualized is $18.58 \%$. Highly persistence factor indicates that "slow decay" toward the mean.We get $4.34 \%$ risk aversion and prove the existence of altering equity premium in PSX during 2008-2015.

\section{References}

[1] Ahmed, A. E. M., \&Suliman, S. Z. (2011). Modeling stock market volatility using garch models evidence from sudan. International Journal of Business and Social Science, 2(23), 114-128.

[2] Baillie, R. T., \& Myers, R. J. (2016). Bivariate garch estimation of the optimal commodity futures hedge, 6(2), 109 124.http://dx.doi.org/10.1002/jae.3950060202.

[3] Beltratti, A., \&Morana, C. (2006). Breaks and persistency: Macroeconomic causes of stock market volatility. Journal of Econometrics, 131, 151-177. http://dx.doi.org/10.1016/j.jeconom.2005.01.007.

[4] Chen, J. (2008). Variance Ratio Tests Of Random Walk Hypothesis of the Euro Exchange Rate, 7(12), 97106.http://dx.doi.org/10.19030/iber.v7i12.3318

[5] Chou, R. Y. (1988). Volatility persistence and stock valuations Some empirical evidence using garch. Journal of Applied Econometrics, 3(4), 279-294. http://dx.doi.org/10.1002/jae.3950030404

[6] Cont, R. (2005). Volatility clustering in financial markets : Empirical facts and agent - based models. A Kirman\& G Teyssiere (eds.): Long Memory in Economics, 21. http://dx.doi.org/10.2139/ssrn.1411462.

[7] Dueker, M. J. (1997). Markov Switching in GARCH Processes and Mean Reverting Stock Market Volatility. Markov switching in garch processes and mean reverting stock market volatility.http://dx.doi.org/10.2307/1392070.

[8] Engle, R. F., \& Patton, A. J. (2001). What good is a volatility model? Quantitative finance volume, $1, \quad 237-$ 245.http://dx.doi.org/10.1088/1469-7688/1/2/305.

[9] Ghahramani, M., \&Thavaneswaran, a. (2006). Financial applications of ARMA models with GARCH errors. The Journal of Risk Finance, 7(5), 525-543. http://dx.doi.org/10.1108/15265940610712678.

[10] Hou, Y., \& Li, S. (2015). Volatility behavior of stock index futures in China: a bivariate GARCH approach. Studies in Economics and Finance, 32(1), 128-154. http://dx.doi.org/10.1108/SEF-10-2013$\underline{0158}$.

[11] Lamoureux, C. G., \&Lastrapes, W. D. (2015). Heteroskedasticity in Stock Return Data: Volume versus GARCH Effects. American Finance Association, 45(1), 221229.http://dx.doi.org/10.2307/2328817.

[12] Liu, M. H., \&Shrestha, K. M. (2008). Analysis of the long-term relationship between macroeconomic variables and the Chinese stock market using heteroskedasticitycointegration. Managerial Finance, 34(11), 744-755.http://dx.doi.org/10.1108/03074350810900479.

[13] Lux, T., \&Marchesi, M. (2000). Volatility Clustering in Financial Markets: a Microsimulation of Interacting Agents. International Journal of Theoretical and Applied Finance, 03(04), 675-702. http://dx.doi.org/10.1142/S0219024900000826.

[14] Magnus, F. J. (2008). Capital Market Efficiency: An Analysis of Weak-form Efficiency on the Ghana Stock Exchange, 5(5), 5-12.

[15] Mangani, R. (2005) "Evidence against Static Assets Pricing on the JSE Securities Exchange of South Africa" Working Paper No. 2005/02, University of Malawi, Chancellor College, Zomba.

[16] Mckerrow, R. (2013). Random walks in frontier stock markets Ghanaian Journal of Economics, 1, 87-103.

[17] Mittnik, S., Robinzonov, N., \&Spindler, M. (2015). Stock marke volatility: identifying major drivers and the Nature of Their Impact Journal of Banking \& Finance, 58, 1-14. http://dx.doi.org/10.1016/j.jbankfin.2015.04.003

[18] Neely, C. J., \& Weller, P. A. (2002). Predicting Exchange Rate Volatility: Genetic Programming versus GARCH and RiskMetrics $^{\mathrm{TM}}$. REVIEW, 43-54.

[19] Omar, M., Hussain, H., Bhatti, G. A., \&Altaf, M. (2013). Testing of random walks in Karachi stock exchange. Elixir Financial Management, 54, 12293-12299.
[20] Tuyen, T. M. (2011). Modeling Volatility Using GARCH Models: Evidence from Vietnam. Economics Bulletin, 31(3), 1935-1942. 